\title{
Cronkhite-Canada syndrome complicated with huge intramucosal gastric cancer
}

\author{
Hideaki Karasawa ${ }^{1}$, Koh Miura ${ }^{1}$, Kazuyuki Ishida ${ }^{2}$, Tomohiko Sase ${ }^{1,2}$, Terutada Kobayashi, \\ Makoto Kinouchi ${ }^{1}$, Mitsunori Okabe ${ }^{1}$, Toshinori Ando ${ }^{1}$, NaOyuki Kaneko ${ }^{1}$, Akihiro Yamamura ${ }^{1}$, \\ Chikashi Shibata ${ }^{1}$, and IwaO SASAKi ${ }^{1}$ \\ ${ }^{1}$ Department of Surgery, Tohoku University Graduate School of Medicine, 1-1 Seiryo-machi, Aoba-ku, Sendai 980-8574, Japan \\ ${ }^{2}$ Department of Pathology, Tohoku University Hospital, Sendai, Japan
}

\begin{abstract}
Cronkhite-Canada syndrome (CCS) is a rare nonhereditary disorder with gastrointestinal polyposis and associated ectodermal changes. This report documents a 59-year-old Japanese man with CCS who underwent a total gastrectomy for gastric tumors. The resected specimen showed a huge gastric adenocarcinoma with numerous polyps throughout the stomach. The cancer was pathologically limited to within the mucosa and its histological structure resembled that of hyperplasia in CCS polyps, which led us to suppose that the carcinoma had arisen from hyperplastic CCS polyps. These results urged us to study the phenotypic expression of mucins, which revealed MUC2(-) and MUC5AC(+) and supported the diagnosis of the tumor as a gastric-type well-differentiated adenocarcinoma. A literature search revealed that 32 gastric carcinomas which developed in patients with CCS were mostly limited to within the submucosa in spite of their huge sizes, and such cancer development in CCS polyposis is therefore not considered to be unusual.
\end{abstract}

Key words Cronkhite-Canada syndrome - Gastric cancer • Immunohistochemistry $\cdot$ Mucin

\section{Introduction}

Cronkhite-Canada syndrome (CCS) is a rare nonhereditary disorder with generalized gastrointestinal polyposis, associated with ectodermal changes such as alopecia, onychodystrophy, and hyperpigmentation [1]. Although previous reports have noted that this syndrome was rarely associated with malignancy [2], recently some reports have noted the association of CCS with carcinomas in the gastrointestinal (GI) tract $[3,4]$. This report documents a Japanese man with CCS who underwent a total gastrectomy for gastric tumors,

Offprint requests to: K. Miura

Received: October 1, 2008 / Accepted: March 19, 2009 and we studied the case in this patient regarding both the pathological findings and the phenotypic expression of mucins. Furthermore, we performed a literature search on gastric cancers associated with CCS, to elucidate the clinicopathological features of such gastric cancers associated with CCS.

\section{Case report}

A 59-year-old Japanese man had been treated for membranous glomerulonephritis (MGN) over the past 30 years. There was no family history of GI polyposis. He had been exhibiting onychodystrophy, hyperpigmentation, and hypogeusia. Gastroscopy, performed because of anemia, revealed numerous polypoidal lesions of various sizes with edematous mucosa throughout the stomach (Fig. 1A). Pathologically, adenocarcinoma cells were detected in the largest polypoidal lesion and an endoscopic examination of the lower GI tract showed a number of scattered small polyps in the colorectum. An upper and lower GI series revealed multiple filling defects throughout the stomach, duodenum, small intestine, and colorectum; thus, he was diagnosed with CCS complicated with gastric cancer. The results of laboratory examinations revealed anemia, hypoproteinemia (total serum protein, $3.6 \mathrm{~g} / \mathrm{dl}$; albumin, $1.8 \mathrm{~g} / \mathrm{dl}$ ), renal dysfunction (blood urea nitrogen, $58 \mathrm{mg} / \mathrm{dl}$, creatinine, $4.1 \mathrm{mg} / \mathrm{dl}$ ), electrolyte abnormality, and low mineral $(\mathrm{Ca}, \mathrm{Zn})$ values. The polyps in the small intestine and colon were small, and he did not have severe GI symptoms; a total gastrectomy was performed with a Rouxen-Y reconstruction. The surgical specimen revealed a giant tumor measuring $92 \times 72 \mathrm{~mm}$ in size, with a number of polyps throughout the whole stomach (Fig. 1B). Histologically, the surface of the giant tumor consisted of well-differentiated and moderately differentiated tubular adenocarcinoma which showed a cribriform pattern (Fig. 2A). The cancerous epithelia had spread 

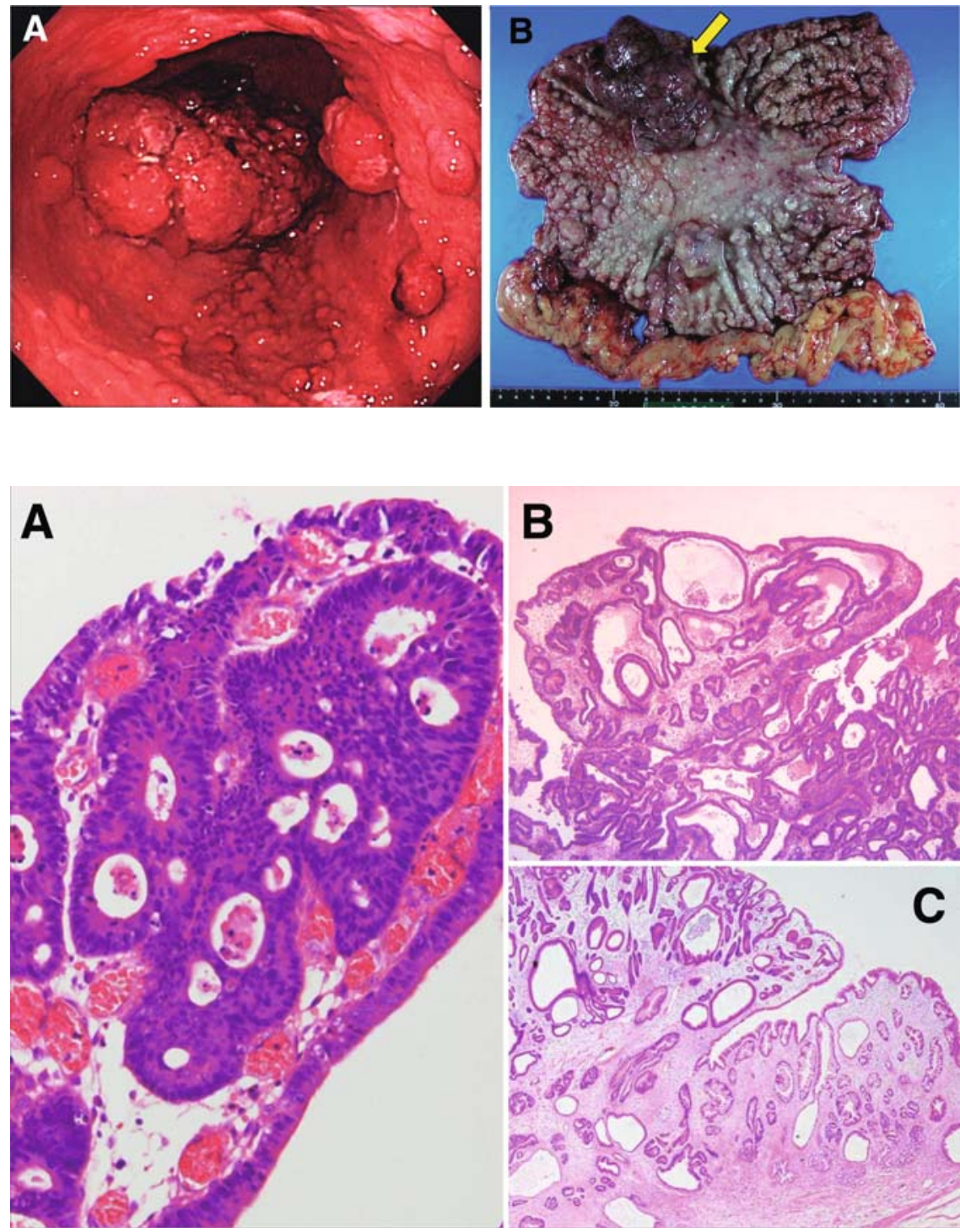

Fig. 1. A Gastroscopy revealed numerous polypoidal lesions of various sizes with edematous mucosa throughout the stomach. B The surgical specimen showed numerous polyps and a giant tumor measuring $92 \times 72 \mathrm{~mm}$ in size (yellow arrow)
Fig. 2. A The surface of the CronkhiteCanada syndrome (CCS) tumor was composed of well-differentiated and moderately differentiated tubular adenocarcinomas which showed a cribriform pattern. B Well-differentiated adenocarcinoma in the CCS tumor. C Hyperplasia with edematous stroma, cystic dilatation of the glands, and infiltration of inflammatory cells, features which are characteristic of CCS polyps. The histological structure shown in $\mathbf{B}$ resembles that shown in $\mathbf{C}$

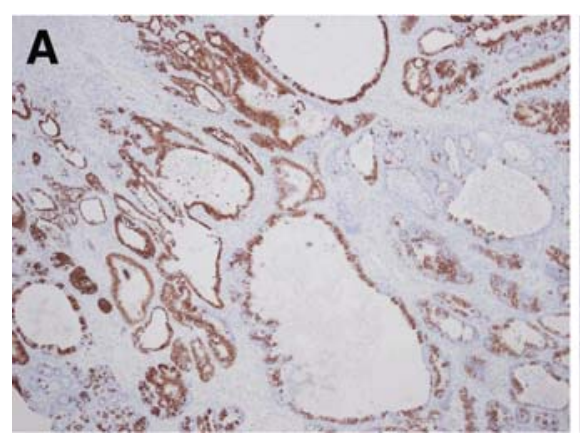

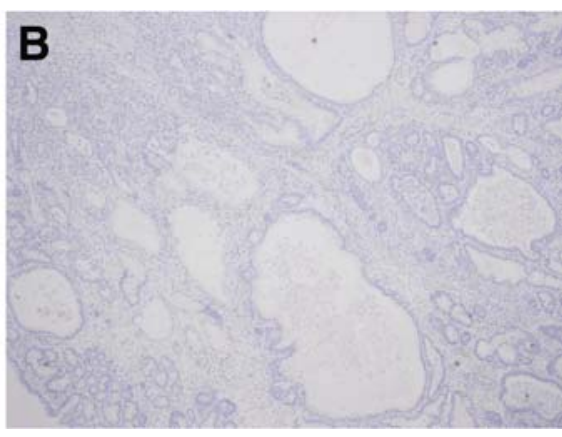

Fig. 3A,B. Immunohistochemical staining in gastric cancer in our patient with CCS. A MUC5AC is positive; $\mathbf{B}$ MUC2 is negative superficially within the mucosal layer, covering almost the whole surface of the tumor; dysplasia was rarely found. There was no finding of lymph node metastasis or distant metastasis; therefore, the histological stage of the gastric cancer was stage IA (T1N0M0) according to the Japanese classification of gastric carcinoma (2nd
English edition) (website: http://www.jgca.jp/gakkai/ foreigner.html). The histological structure of the welldifferentiated adenocarcinoma (Fig. 2B) resembled that of hyperplasia, with edematous stroma, cystic dilatation of the glands, and infiltration of inflammatory cells, features that are characteristic of CCS polyps (Fig. 2C). 
The identity of the pathological findings with those of CCS polyps led us to suppose that the carcinoma had arisen from hyperplastic CCS polyps.

Our notion on the pathological findings and the report by Kushima et al. [5], which referred to "adenocarcinoma arising from hyperplastic polyps," urged us to study the phenotypic expression of the mucins in the gastric cancer tissue. This study revealed that MUC5AC was strongly positive, but MUC2 and MUC6 were negative (Fig. 3). The results supported the diagnosis of the tumor as a gastric-type well-differentiated adenocarcinoma; the concept of such tumors has recently become accepted [5]. In addition, pathology examination detected Helicobacter pylori infection. The patient showed marked alleviation of his hypoproteinemia (total serum protein, $6.1 \mathrm{~g} / \mathrm{dl}$; albumin, $3.3 \mathrm{~g} / \mathrm{dl}$ ) and was discharged subsequently without any complications.

\section{Discussion}

CCS was first reported in 1955 as generalized GI polyposis with ectodermal changes, including alopecia, hyperpigmentation, and onychodystrophy [1]. Since that time CCS has been reported mostly in Japan. Goto [6] reviewed 154 CCS cases before 1985 and reported that 110 of the patients $(71.4 \%)$ were Japanese. The clinical manifestations of CCS include not only GI symptoms such as diarrhea, anorexia, weight loss, abdominal pain, and vomiting, but also ectodermal changes such as hypogeusia, onychodystrophy, hair loss, and hyperpigmentation [7]. Hypoproteinemia caused by protein loss and malabsorption have been observed frequently; furthermore, electrolyte and mineral abnormalities may be manifested. The present patient showed symptoms of onychodystrophy, hyperpigmentation, severe hypoproteinemia, electrolyte abnormality, and low mineral $(\mathrm{Ca}, \mathrm{Zn})$ values. Because he had been treated for MGN, the hypoproteinemia before the surgical resection was therefore not thought to have been caused by CCS alone. On the other hand, Sagara et al. [8] reported a CCS patient who completely recovered from hypoproteinemia after a gastrectomy; also, in the present patient, the hypoproteinemia was markedly alleviated after the total gastrectomy. This suggested that the protein had been mainly lost from the stomach in both these patients.

In our patient, the histological structure of welldifferentiated adenocarcinoma in the tumor (Fig. 2B) resembled that of hyperplasia in other CCS polyps (Fig. 2C), which led us to suppose that the carcinoma had arisen from the hyperplastic CCS polyps. Kushima et al. [5] documented that $11(78.6 \%)$ of 14 differentiated-type carcinomas in hyperplastic polyps were gastric-type adenocarcinomas. Recently, the concept of gastric-type well-differentiated adenocarcinoma, a disease entity which is different from "intestinal-type" and which arises in nonintestinalized gastric mucosa, has been established following the discovery of MUC genes coding core proteins of mucin, although differentiated adenocarcinomas of the stomach have been commonly thought to arise from intestinal metaplasia [5]. These results urged us to study the phenotypic expression of mucins in the gastric cancer tissue. In our patient, MUC5AC, which is expressed in the superficial foveolar epithelia, was positive, and MUC2, which is expressed in intestinal metaplasia, was negative (Fig. 3). These results suggested that this cancer could be classified as gastric-type, not intestinal-type, welldifferentiated adenocarcinoma.

CCS has rarely been reported to be associated with carcinomas [2]; however, recently, the development of cancer of the stomach in CCS patients has been reported in some articles. Egawa et al. [3] reported an association rate between CCS and gastric cancer of 5.1\% (19/374 cases) and suggested that CCS was a high-risk condition for stomach malignancy. Until now, 32 CCS cases associated with gastric cancers have been reported in the literature, and all of these cases were in Japanese patients (Table 1) $[3,8,9,10]$. One important reason that gastric carcinoma has been described solely in Japanese patients with CCS could be because of the health care surveillance system in Japan, especially regarding the progress of mass screening and regular check-ups with endoscopic examinations. Another possible reason may be the spread of Helicobacter pylori infection. Recently, the association of $H$. pylori infection, especially cytotoxin-associated gene $\mathrm{A}(\operatorname{Cag} A)$ positive $H$. pylori strain infection, with the development of stomach cancer, has been actively discussed [11]; furthermore, a high incidence of gastric cancer is mostly seen in those regions where east Asian type $\operatorname{Cag} A$ positive $H$. pylori is predominant, such as in Japan [12]. It is therefore possible that $H$. pylori infection is associated with the development of gastric cancer in CCS patients. Because there have been no reports documenting $H$. pylori infection in CCS patients, except for our patient, it is difficult to discuss whether H. pylori infection is associated with the development of stomach cancer in CCS patients. This subject should be the next goal to be clarified.

As summarized in Table 1, in gastric cancers that developed in CCS patients, the depth of cancer invasion was limited to within the submucosa in spite of their large sizes, and they were frequently well-differentiated histological types. The invasion in our present patient was limited to within the mucosal layer in spite of its huge size as well. Considering these results, gastric cancers associated with CCS may demonstrate a low grade of malignancy. A literature search was carried out 
Table 1. Reported cases of Cronkhite-Canada syndrome complicated with gastric cancer

\begin{tabular}{|c|c|c|c|c|c|c|c|}
\hline No. & Sex & $\begin{array}{c}\text { Age } \\
\text { (years) }\end{array}$ & $\begin{array}{c}\text { Macroscopic } \\
\text { type }\end{array}$ & $\begin{array}{l}\text { Greatest } \\
\text { dimension } \\
\text { of tumor } \\
(\mathrm{mm})\end{array}$ & $\begin{array}{c}\text { Depth } \\
\text { of } \\
\text { tumor } \\
\text { invasion }\end{array}$ & $\begin{array}{l}\text { Histological } \\
\text { type }\end{array}$ & Reference \\
\hline 1 & $\mathrm{~F}$ & 46 & Type 1 & 60 & $\mathrm{~T} 1(\mathrm{M})$ & tub1 & Nakamura et al. Stomach and Intestine $1979 ; 14: 1217-22 .^{a}$ \\
\hline 2 & M & 70 & Type 1 & 70 & $\mathrm{~T} 2$ (SS) & tub1+sq & Yokoyama et al. Stomach and Intestine $1983 ; 18: 981-5 .^{a}$ \\
\hline 3 & M & 71 & Type 1 & & $\mathrm{~T} 1(\mathrm{SM})$ & tub1 & {$[8]$} \\
\hline 4 & M & 51 & & & $\mathrm{~T} 2$ (SS) & & Sugimura et al. Nichidai Ishi $1984 ; 43: 327 .^{\text {b }}$ \\
\hline 5 & $\mathrm{~F}$ & 72 & & & $\mathrm{~T} 1(\mathrm{M})$ & tub2+por & Isobe et al. Prog Dig Endosc $1985 ; 26: 243-6 .^{\text {b }}$ \\
\hline 6 & M & 61 & & & $\mathrm{~T} 1(\mathrm{SM})$ & & Tsushita et al. Jpn J Gastroenterol $1985 ; 82: 243-6 .^{\text {b }}$ \\
\hline 7 & $\mathrm{~F}$ & 59 & Type 1 & 100 & $\mathrm{~T} 1(\mathrm{M})$ & tub1 & Uchida et al. Stomach and Intestine $1986 ; 21: 559-63 .^{a}$ \\
\hline 8 & $\mathrm{M}$ & 78 & & & & & Koido et al. Jpn J Gastroenterology 1986;83:565. ${ }^{\text {b }}$ \\
\hline 9 & M & 59 & Type 1 & & & tub1 & Yoshida et al. J Jpn Surg Assoc 1988;49:138. ${ }^{\text {b }}$ \\
\hline 10 & $\mathrm{M}$ & 68 & & & $\mathrm{~T} 1(\mathrm{M})$ & tub1 & Nouchi et al. Gastroenterol Endosc $1990 ; 32: 2773 .^{\text {b }}$ \\
\hline 11 & M & 72 & & & T1 (M) & tub1 & Hasegawa et al. Gastroenterol Endosc 1990;32:2774. ${ }^{\text {b }}$ \\
\hline 12 & $\mathrm{~F}$ & 78 & & & & & Ogawa et al. J Jpn Surg Assoc 1990;51:2790. ${ }^{\text {b }}$ \\
\hline 13 & M & 70 & & & $\mathrm{~T} 2(\mathrm{SS})$ & por+sig & Kumano et al. Hiroshima Med J 1991;44:637-42. \\
\hline 14 & M & 69 & Type 0 IIc & 30 & $\mathrm{~T} 1$ (SM) & tub1 & {$[9]$} \\
\hline \multirow[t]{2}{*}{15} & M & 54 & Type 2 & 50 & $\mathrm{~T} 2(\mathrm{SS})$ & tub2 & Fushida et al. J Jpn Surg Assoc 1994;55:2854-8. ${ }^{\text {a }}$ \\
\hline & & & Type 1 & 50 & $\mathrm{~T} 1$ (M) & tub1 & \\
\hline 16 & M & 72 & Type 2 & & $\mathrm{~T} 2$ (SS) & por & Yabushita et al. Jpn J Gastroenterol Surg 1997;30:387. ${ }^{\text {b }}$ \\
\hline 17 & $\mathrm{M}$ & 54 & & & & & Nasu et al. J Jpn Radiol Soc 1997;57:295-6. ${ }^{\text {b }}$ \\
\hline 18 & $\mathrm{M}$ & 62 & & & $\mathrm{~T} 1(\mathrm{M})$ & tub1 & Daidou et al. Shiga Med J 1998;21:25-9.' \\
\hline 19 & M & 50 & Type 3 & 45 & $\mathrm{~T} 2(\mathrm{MP})$ & tub1+tub2 & Konishi et al. J Jpn Surg Assoc 1998;59:2801-7. ${ }^{\text {a }}$ \\
\hline \multirow[t]{3}{*}{20} & M & 61 & & & $\mathrm{~T} 1$ & tub1 & Tokubayashi et al. Shiga Med J 1998;20:62-3. ${ }^{\text {b }}$ \\
\hline & & & & & $\mathrm{T} 1$ & pap & \\
\hline & & & & & $\mathrm{T} 1$ & muc & \\
\hline 21 & M & 52 & & & $\mathrm{~T} 2(\mathrm{MP})$ & tub $2+$ por & Shiraishi et al. Gastroenterol Endosc 1999;41:1938. ${ }^{\text {b }}$ \\
\hline \multirow[t]{3}{*}{22} & M & 70 & Type 1 & 70 & $\mathrm{~T} 1$ (SM) & tub1 & {$[10]$} \\
\hline & & & Type 1 & 20 & $\mathrm{~T} 1(\mathrm{M})$ & tub1 & \\
\hline & & & Type 1 & 20 & $\mathrm{~T} 1(\mathrm{M})$ & tub1 & \\
\hline 23 & M & 73 & Type 2 & 22 & $\mathrm{~T} 2$ (SS) & tub2 & Ogami et al. J Jpn Surg Assoc 2000;61:471. ${ }^{\text {a }}$ \\
\hline 24 & M & 52 & Type 1 & 40 & $\mathrm{~T} 2(\mathrm{MP})$ & por & [3] \\
\hline 25 & M & 46 & Type 1 & 20 & $\mathrm{~T} 1$ (SM) & tub2 & Kurisu et al. Proc Jpn Soc Pathol 2000;89:364. ${ }^{\text {b }}$ \\
\hline \multirow[t]{3}{*}{26} & $\mathrm{M}$ & 62 & & & $\mathrm{~T} 1$ (SM) & muc & Kazuki et al. Proc Jpn Soc Pathol 2002;91:269. ${ }^{\text {b }}$ \\
\hline & & & & & $\mathrm{T} 1(\mathrm{M})$ & tub1+tub2 & \\
\hline & & & & & $\mathrm{T} 1$ (M) & pap & \\
\hline 27 & M & 59 & Type 1 & & $\mathrm{~T} 2$ (MP) & por & Kazuki et al. Proc Jpn Soc Pathol 2002;91:269. ${ }^{\text {b }}$ \\
\hline 28 & M & 73 & & & $\mathrm{~T} 2(\mathrm{SS})$ & tub2 & Ikeda et al. Jpn J Gastroenterol Surg 2003;36:1066. ${ }^{\text {b }}$ \\
\hline 29 & M & 68 & Type 1 & 100 & T2 (SS) & por, $\operatorname{AFP}(+)$ & Yokoyama et al. J Jpn Surg Assoc 2003;64:3052-7. \\
\hline 30 & M & 71 & Type 1 & & $\mathrm{~T} 1(\mathrm{M})$ & tub1 & Hayashi et al. Rinsho Derma 2004;47:770-1. \\
\hline \multirow[t]{4}{*}{31} & M & 71 & Type 2 & 30 & $\mathrm{~T} 1$ (SM) & por & Abe et al. Prog Dig Endosc 2005,67:76-7. ${ }^{\text {b }}$ \\
\hline & & & Type $0 \mathrm{IIb}$ & & & tub1 & \\
\hline & & & Type 0 IIb & & & tub1 & \\
\hline & & & Type 1 & 30 & $\mathrm{~T} 1(\mathrm{M})$ & tub1 & \\
\hline 32 & M & 59 & Type 1 & 92 & $\mathrm{~T} 1(\mathrm{M})$ & tub1 & Present case \\
\hline
\end{tabular}

According to the Japanese classification of gastric carcinoma, 2nd English edition (website: http://www.jgca.jp/gakkai/foreigner.html)

${ }^{a}$ In Japanese with English abstract

${ }^{\mathrm{b}}$ In Japanese

to analyze gastric cancers in 32 Japanese CCS patients, and their clinicopathological features were compared with those of 12533 gastric cancers treated at the Cancer Institute Hospital (Tokyo, Japan) from 1946 to 2004 [13]. This revealed that the gastric cancers in CCS patients were mostly limited to within the submucosa (T1; 24 of 36 lesions; $66.6 \%$ ) in spite of their large sizes. On the other hand, 4514 lesions (36.0\%) from the Cancer Institute Hospital were within T1. In a study focusing on gastric cancer cases with available informa- tion on both their tumor depth and diameter, the average diameter of $\mathrm{T} 1$ gastric cancer in CCS was $47.5 \mathrm{~mm}$, which was much greater than that in the common gastric cancers observed at the Cancer Institute Hospital $(33.0 \mathrm{~mm})$. These results may support the notion that the steps of carcinogenesis in CCS are different from those in common gastric cancers.

In clinical follow up, it is important to remember the clinicopathological features of CCS tumors, including the findings that CCS tumors are associated with malig- 
nancies more frequently than was previously expected, and gastric cancers that develop from CCS tumors are mostly limited to within $\mathrm{T} 1$ in spite of their large sizes. Furthermore, with the findings of an immunohistochemical study of the phenotypic expression of mucins, we propose that gastric adenocarcinomas associated with CCS polyps should therefore be classified as gastrictype well-differentiated adenocarcinomas, in accordance with this recently established concept.

\section{References}

1. Cronkhite LW Jr, Canada WJ. Generalized gastrointestinal polyposis; an unusual syndrome of polyposis, pigmentation, alopecia and onychotrophia. N Engl J Med 1955;252:1011-5.

2. Nonomura A, Ohta G, Ibata T, Shinozaki K, Nishino T. Cronkhite-Canada syndrome associated with sigmoid cancer: case report and review of 54 cases with the syndrome. Acta Pathol Jpn 1980;30:825-45.

3. Egawa T, Kubota T, Otani Y, Kurihara N, Abe S, Kimata M, et al. Surgically treated Cronkhite-Canada syndrome associated with gastric cancer. Gastric Cancer 2000;3:156-60.

4. Yamaguchi K, Ogata Y, Akagi Y, Sasatomi T, Ozaki K, Ohkita A, et al. Cronkhite-Canada syndrome associated with advanced rectal cancer treated by a subtotal colectomy: report of a case. Surg Today 2001;31:521-6.
5. Kushima R, Vieth M, Borchard F, Stolte M, Mukaisho K, Hattori T. Gastric-type well-differentiated adenocarcinoma and pyloric gland adenoma of the stomach. Gastric Cancer 2006;9:177-84.

6. Goto A. Cronkhite-Canada syndrome: epidemiological study of 110 cases reported in Japan. Nippon Geka Hokan 1995;64:3-14.

7. Murata I, Yoshikawa I, Endo M, Tai M, Toyoda C, Abe S, et al. Cronkhite-Canada syndrome: report of two cases. J Gastroenterol 2000;35:706-11.

8. Sagara K, Fujiyama S, Kamuro Y, Tashiro A, Sato T. CronkhiteCanada syndrome associated with gastric cancer: report of a case. Gastroenterol Jpn 1983;18:260-6.

9. Kaneko Y, Kato H, Tachimori Y, Watanabe H, Ushio K, Yamaguchi $\mathrm{H}$, et al. Triple carcinomas in Cronkhite-Canada syndrome. Jpn J Clin Oncol 1991;21:194-202.

10. Watanabe T, Kudo M, Shirane H, Kashida H, Tomita S, Orino A, et al. Cronkhite-Canada syndrome associated with triple gastric cancers: a case report. Gastrointest Endosc 1999;50: 688-91.

11. Blaser MJ, Perez-Perez GI, Kleanthous H, Cover TL, Peek RM, Chyou PH, et al. Infection with Helicobacter pylori strains possessing cagA are associated with an increased risk of developing adenocarcinoma of the stomach. Cancer Res 1995;55:2111-5.

12. Yamaoka Y, Kato M, Asaka M. Geographic differences in gastric cancer incidence can be explained by differences between Helicobacter pylori strains. Intern Med 2008;47:1077-83.

13. Nakajima T, Yamaguchi T. Gastric cancer data-base in Cancer Institute Hospital (1946-2004) with CD-ROM. Tokyo: Kanehara; 2006. 